\title{
Magnetic Characterization and Self-heating of Various Magnetic Nanoparticles for Medical Applications
}

\author{
Asahi Tomitaka ${ }^{1 *}$, Hiroki Kobayashi ${ }^{1}$, Tsutomu Yamada ${ }^{1}$, Minhong Jeun ${ }^{2}$, Seongtae Bae $^{2}$ and Yasushi Takemura ${ }^{1}$
}

Abstract- Magnetic and self-heating properties of $\mathrm{CoFe}_{2} \mathrm{O}_{4}$, $\mathrm{MgFe}_{2} \mathrm{O}_{4}$ and $\mathrm{NiFe}_{2} \mathrm{O}_{4}$ nanoparticles were evaluated. $\mathrm{MgFe}_{2} \mathrm{O}_{4}$ and $\mathrm{NiFe}_{2} \mathrm{O}_{4}$, whose coercive forces are lower than that of $\mathrm{CoFe}_{2} \mathrm{O}_{4}$, exhibited higher temperature rise in self-heating excited by ac magnetic field of $150 \mathrm{Oe}$ at $10 \mathrm{kHz}$. The energy efficiency of magnetic field in generating self heating of these ferrite nanoparticles is also analyzed. It was also evaluated the cytocompatibility of each ferrite nanoparticles.

\section{BACKGROUND}

Magnetic nanoparticles exhibit unique properties, such as conjugation of biological materials, guidance by magnet and heat dissipation in alternating magnetic fields. Owing to these properties, magnetic particles can be used for medical applications such as the carrier of drug delivery system and the heat source of hyperthermia [1-3]. The availability of transferring the anticancer drug to tumor reduces side effects in chemotherapy. And heating tumor selectively enables less side effects and repeating treatment as compared to surgery, chemotherapy and radiation therapy. It is significant for drug delivery system and hyperthermia to use the nanoparticles which exhibit high magnetic force and induce high temperature rise. Here the magnetization characteristics and the temperature rise of various magnetic nanoparticles are studied. The magnetic field which generates self-heating efficiently is also discussed. Moreover, magnetic nanoparticles should be biocompatible for biomedical applications. Many cytotoxicity studies on magnetite coated with some materials were reported, but there are few on other ferrite nanoparticles [4]. Therefore we reported the cytotoxicity of those magnetic nanoparticles on HeLa cells.

\section{CURRENT RESUlT}

The magnetization curves of $\mathrm{CoFe}_{2} \mathrm{O}_{4}(146 \mathrm{~nm}), \mathrm{MgFe}_{2} \mathrm{O}_{4}$ $(130.2 \mathrm{~nm})$ and $\mathrm{NiFe}_{2} \mathrm{O}_{4}(130.7 \mathrm{~nm})$ nanoparticles measured by using a vibrating sample magnetometer (VSM) at room temperature with the maximum field of $10 \mathrm{kOe}$ are shown in Fig.1. The coercivity and remanent magnetization of them are

${ }^{1}$ Department of Electrical and Computer Engineering, Yokohama National University, Japan

${ }^{2}$ Biomagnetics Laboratory, Department of Electrical and Computer Engineering, National University of Singapore, Singapore 117576, Singapore. *e-mail: d09sd105@ynu.ac.jp shown in Fig.2. The magnetization values of those nanoparticles were less than their corresponding bulk values. It is also observed that the smaller size particles exhibit smaller saturation magnetization. This reduced magnetization of nanosized magnetic particles is explained by the surface spin disorder which is due to cation redistribution or the formation of spin glass like structure in the near-surface layers $[6,7]$. Fig. 3 shows time dependence on temperature rise of the samples. The ac field frequency was $10 \mathrm{kHz}$ and amplitude was 150 Oe. $\mathrm{CoFe}_{2} \mathrm{O}_{4}$ exhibited little self-heating temperature rise, which was attributed to its large coerciviy [8] (1030 Oe shown in Fig.2). The magnetic field of $150 \mathrm{Oe}$ is not adequate to open the hysteresis area. On the other hand, $\mathrm{MgFe}_{2} \mathrm{O}_{4}$ and $\mathrm{NiFe}_{2} \mathrm{O}_{4}$ exhibited higher temperature rise because of the lower coercive forces (below $100 \mathrm{Oe}$ ). In vitro cytocompatibility study of $\mathrm{CoFe}_{2} \mathrm{O}_{4}(26.5 \mathrm{~nm}), \mathrm{MgFe}_{2} \mathrm{O}_{4}(27.4 \mathrm{~nm})$ and $\mathrm{NiFe}_{2} \mathrm{O}_{4}$ (20-30 nm) was done on HeLa cells. Fig. 4 shows the survival rate of $\mathrm{HeLa}$ cells exposed to those samples at the concentration of $200 \mu \mathrm{g} / \mathrm{ml}$ for 3 days. In Fig.4, only $\mathrm{NiFe}_{2} \mathrm{O}_{4}$ induced lower cell viability and the $\mathrm{HeLa}$ cells exposed to $\mathrm{CoFe}_{2} \mathrm{O}_{4}$ and $\mathrm{MgFe}_{2} \mathrm{O}_{4}$ exhibited slight influence on their survival rate.

The magnetization curve, self-heating and cytocompatibility of $\mathrm{CoFe}_{2} \mathrm{O}_{4}, \mathrm{MgFe}_{2} \mathrm{O}_{4}$ and $\mathrm{NiFe}_{2} \mathrm{O}_{4}$ were reported. $\mathrm{NiFe}_{2} \mathrm{O}_{4}$ has high temperature rise in ac magnetic field but induces lower cell viability on HeLa cells which should be coated with biocompatible materials.

\section{REFERENCES}

[1] Q. A. Pankhurst, J. Connolly, S. K. Jones, J. Dobson, J. Phys. D: Appl. Phys. 36 (2003) R167-R181.

[2] B. Chertok, B. A. Moffat, A. E. David, F. Yu, C. Bergemann, B. D. Ross, V. C. Yang, Biomaterials 29 (2008) 487-496.

[3] A. K. Gupta, M. Gupta, Biomaterials 26 (2005) 3995-4021.

[4] P. Pradhan, J. Giri, R. Banerjee, J. Bellarea, D.Bahadur, J. Magn. Magn. Mater. 311 (2007) 282

[5] J. Giri, P. Pradhan, V. Somani, H. Chelawat, S. Chhatre, R. Banerjee, D. Bahadur, J. Magn. Magn. Mater. 320 (2008) 724-730.

[6] X. Huang, Z. Chen, J. Magn. Magn. Mater. 280 (2004) 37-43 [7] V. Šepelák, I. Bergmanna, D. Menzelc, A. Feldhoffd, P. Heitjansd, F.J. Litterstc, K.D. Beckera, J. Magn. Magn. Mater. 316 (2007) e764-e767. [8] P. Pradhan, J. Giri, G. Samanta, H. D. Sarma, K. P. Mishra, J. Bellare, R. Banerjee, D. Bahadur, J. Biomed. Mater. Res., Part B: Appl. Biomater. 81B (2007) 12-22. 